\title{
CERN seeks an extra \$330 million for LHC
}

Munich. The council of the European Laboratory for Particle Physics (CERN) has confirmed its commitment to the construction of the planned Large Hadron Collider (LHC), and has asked for proposals from CERN management as to how non-member states might contribute towards its financing.

Christopher Llewellyn Smith, who takes over next month as the director-general of CERN, told a meeting of the council in
Geneva last week that the most recent cost estimates, including total costs of experimental areas and experiments, were about SFr2.6 billion (US\$1.7 billion) over the tenyear period 1995-2005.

The machine itself will cost SFr2.23 billion of the total, a price which has been approved as "realistic" by an independent review committee, headed by Robert Aymar of the French Atomic Energy Commission

\section{Old AIDS news dressed up as new}

London. The Sunday Times has again attacked both Nature and its editor John Maddox for allegedly failing to publicize the views of those who do not believe HIV causes AIDS. In a headline printed over six readers' letters in its issue of 19 December, the newspaper wrote that "the world's leading scientific journal" is playing a "sinister game".

But it did not present any new evidence in support of its own views, nor did it report on scientific research being done on AIDS. It limits its coverage to printing the readers letters' - four in favour of and two attacking its stance - and to expanding one of these into a short news story.

The only letter from a researcher working on AIDS was from John Moore of the Aaron Diamond Research Center in New York. Moore points out that, rather than ignoring the views of molecular biologist Peter Duesberg that HIV does not cause AIDS, he and other researchers have rejected Duesberg's arguments as scientifically unsound. He says that the case for HIV has been "proven to our intellectual satisfaction".

In contrast, Dennis Parke, a retired professor of biochemistry at the University of Surrey, writes in support of the Sunday Times' "exposé", and puts forward his own theory of AIDS - - which includes HIV infection. Parke says that he had to start his own journal to publish "several controversial papers rejected by other journals for their heretical views".

Parke's views were repeated in a news story elsewhere in early editions of the newspaper, which repeated his claim to have seen AIDS cases in 1968. But neither the letter nor the news report points out that it is widely recognized in the medical community that AIDS has been around for even longer; two cases from the 1950s have been reported in the clinical literature.

Similarly, the newspaper reports under the logo "AIDS: why we won't be silenced" - the discovery of several HIVnegative cases of Kaposi's sarcoma as if this is a new finding. Again, however, these cases have been reported in the medical

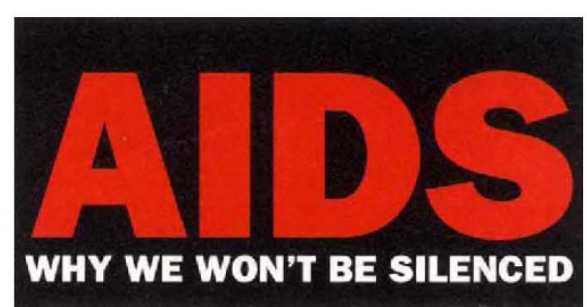

As the Sunday Times sees it

research literature for some time.

Three of the remaining four letters accused Nature of "scientific censorship" for allegedly failing to report the views of people who do not believe that AIDS is caused by HIV. One gives most prominence to Nature's alleged handling of scientific papers on a different topic. The remaining letter accuses the Sunday Times of using its "campaign" on AIDS to increase the circulation of the newspaper.

Other British newspapers have reported on the argument between Nature and the Sunday Times. Simon Jenkins concluded in the Times on Saturday (18 December) that AIDS researchers (and others) should declare who funds their research, clearly unaware that published scientific papers invariably carry this information.

In a different vein, the Guardian wrote in its issue of 12 December that, while many agree that AIDS is not spreading through the heterosexual population at the rate which was predicted six years ago, "it is the Sunday Times alleged lack of balance which has alienated the establishment".

In reply to the Guardian article, Andrew Neil, editor of the Sunday Times, said that the idea of there being some doubt about the role of HIV in causing AIDS had been suppressed "in most of the media with all the rigour of a one-party state".

Neil also said that the Sunday Times had found it difficult to print letters critical of what he calls the papers "revisionist stance" because they contain "abuse rather than reasoned argument". Elsewhere in this issue (page 716) we reprint one of the letters the newspaper refused to publish earlier this year.

Maxine Clarke
(CEA). (This committee also approved the technical feasibility of the current design, and concluded that the project "should be approved rapidly.")

But constructing the $\mathrm{LHC}$ at the proposed price and timetable will require an additional contribution of SFr500 million from non-member countries, if contributions of CERN member states are to be kept as promised at their current level. As a result, the council has urged CERN to report back within three months on ways which other countries might become involved.

"Council wishes that such involvement should be on the understanding that usage on a significant scale must involve the provision of resources to suit both CERN and the non-member states concerned," it said in a statement issued after the meeting.

In pursuit of this goal, Llewellyn Smith will continue to investigate the possibility of reaching cooperative agreements on LHC experiments, particularly with US and Japanese scientists following the abandonment by the United States of the Super Conducting Supercollider (SSC).

At the same time, he has been asked to prepare a series of alternative scenarios, and to indicate how the SFr500 million deficit might be accommodated in the absence of international funding, for example by stretching out the 10-year construction timescale, or trimming planned experiments.

In an address to last week's council meeting, Llewellyn Smith said that LHC would welcome intellectual input from non-member state physicists. But he underlined that participation should be linked with a financial contribution to the project.

Before the demise of the SSC, US high energy particle physicists had open access to CERN facilities such as the Large Electron-Positron Collider (LEP) because approximately equal numbers of physicists from CERN member states were able to work on US-based projects. "Now this equilibrium has completely changed," says Lyndon Evans, incoming director of the LHC. "US scientists will now be expected to make a contribution to the cost of the LHC if they want to take part in experiments."

Last week's council meeting also approved a proposal designed to increase the chances of smaller member states obtaining construction and other contracts, a sore point with countries such as Spain which claim to have been unfairly treated in the past.

The council agreed that, in future, if the lowest bid for a particular contract comes from a country which already enjoys a high level of contracts in proportion to its financial contribution, then CERN will enter into negotiations the two lowest bidders from countries which have "poorly balanced return coefficients" to see if a contract can be agreed with them. 